\title{
Preoperative cerebral and renal oxygen saturation and clinical outcomes in pediatric patients with congenital heart disease
}

\author{
Junichi Saito ${ }^{1}$ - Daiki Takekawa ${ }^{1}$ Jun Kawaguchi ${ }^{1} \cdot$ Takuya Suganuma $^{1} \cdot$ Mao Konno $^{1} \cdot$ Satoko Noguchi $^{1}$. \\ Takaharu Tokita $^{2} \cdot$ Eiji Hashiba $^{3} \cdot$ Kazuyoshi Hirota ${ }^{1}$
}

Received: 7 September 2018 / Accepted: 14 January 2019 / Published online: 21 January 2019

(c) Springer Nature B.V. 2019

\begin{abstract}
We examined the predictability of preoperative cerebral and renal $\mathrm{rSO}_{2}$ values for outcomes in pediatric patients undergoing cardiac surgery under cardiopulmonary bypass (CPB). Patients who underwent pediatric cardiac surgery under CPB between September 2015 and September 2017 were enrolled in this study. Patients monitored with both cerebral and renal $\mathrm{rSO}_{2}$ at the beginning of surgery were included. The primary outcome was the prediction of outcomes after pediatric cardiac surgery. Outcome was defined as any of: (1) death within 30 days after surgery, or the need for (2) renal replacement therapy or (3) extracorporeal membrane oxygenation, (4) shorten mechanical ventilator-free day,(5) shorten ICU-free survival day. We included 59 patients: cyanotic $n=31$; non-cyanotic $n=28$. Among all patients, $15(25 \%)$ had poor outcomes, including three deaths. The cerebral and renal $\mathrm{rSO}_{2}$ values were significantly lower in the cyanotic patients with poor outcomes compared to those without poor outcomes (cerebral: $59 \pm 11$ vs. $50 \pm 5, p=0.021$; renal: $59 \pm 15$ vs. $51 \pm 14, p=0.015$ ) but only the renal $\mathrm{rSO}_{2}$ value was significantly lower in the non-cyanotic patients $(77 \pm 10 \mathrm{vs.} 61 \pm 14, \mathrm{p}=0.011)$. The cut-off value $(51 \%)$ of cerebral $\mathrm{rSO}_{2}$ were associated with risk of mechanical ventilator-free day and ICU-free survival day [ORs of 22.8 (95\% CI 2.21-235.0, $\mathrm{p}=0.0087)$ and $15.8(95 \% \mathrm{CI} 1.53-164.0, \mathrm{p}=0.0204)$, respectively] in the cyanotic patients. The cut-off value (66\%) of cerebral $\mathrm{rSO}_{2}$ value was associated with risk of mechanical ventilator-free day [OR of $11.3(95 \%$ CI 1.05-25.3, $\mathrm{p}=0.0456)$ ] and the cut-off value $(66 \%)$ of renal $\mathrm{rSO}_{2}$ value was associated with risk of ICU-free survival day [ORs of $33.0(95 \% \mathrm{CI} 2.25-484.0, \mathrm{p}=0.0107)$ ] in the noncyanotic patients. The preoperative low $\mathrm{rSO}_{2}$ values were associated with outcomes including 30-day mortality and might be reflective of the severity of cardiopulmonary function. Further studies are needed to confirm our results.
\end{abstract}

Keywords Congenital heart disease $\cdot$ Regional oxygen saturation · Cardiopulmonary dysfunction · Cerebrovascular autoregulation

\section{Introduction}

Near-infrared spectroscopy uses an infrared light source to measure regional oxyhemoglobin saturation $\left(\mathrm{rSO}_{2}\right)$ noninvasively into the tissue bed. Cerebral $\mathrm{rSO}_{2}$ values are correlated with the invasive venous oxygen saturation $\left(\mathrm{ScvO}_{2}\right)$ values obtained after a patient's congenital heart surgery [1]. Low cerebral $\mathrm{rSO}_{2}$ values have been associated with

IRB contact information: This study protocol was approved by Hirosaki University Ethics Committee. E-mail: fix-you@ hotmail. co.jp.

Junichi Saito

saitoj@hirosaki-u.ac.jp

Extended author information available on the last page of the article an increased risk of hypoxic-ischemic brain injury [2, 3] and low renal $\mathrm{rSO}_{2}$ values can be a good predictor of acute kidney injury after cardiac surgery in both adult and pediatric patients [4-7]. It was reported that in adult cardiac patients, the preoperative $\mathrm{rSO}_{2}$ value may reflect the severity of cardiopulmonary dysfunction and be associated with short- and long-term mortality and morbidity [8]. However, the question of whether preoperative $\mathrm{rSO}_{2}$ values could be used to predict poor outcomes in patients undergoing congenital heart surgery has not been well determined due to the complicated cardiac physiology and impaired cerebral blood flow in infants with congenital heart disease [9-11]. We conducted the present study to evaluate whether preoperative cerebral and renal $\mathrm{rSO}_{2}$ values could have association 
with each outcome in pediatric patients undergoing cardiac surgery under cardiopulmonary bypass (CPB).

\section{Methods}

\subsection{Study design}

This retrospective observational study was approved by the Medical Ethics Committee of our hospital (Permission No. 2017-1110). Electronic medical and anesthesia records of patients who underwent pediatric cardiac surgery under CPB at our hospital between September 2015 and September 2017 were reviewed. Patients whose cerebral and renal $\mathrm{rSO}_{2}$ values were monitored at the beginning of surgery were included. Monitoring of $\mathrm{rSO}_{2}$ values was continued until the end of the surgery. Patients who had required extracorporeal membrane oxygenation (ECMO) preoperatively were excluded, because ECMO has a strong effect on $\mathrm{rSO}_{2}$ values [12]. In the operating room, after the induction of anesthesia, pediatric-sized oximetry sensors were placed on the patient's forehead and the right flank below the costovertebral angle overlying the right kidney. An INVOS 5100B oximeter (Somanetics, Troy, MI) was used to monitor both the cerebral and renal $\mathrm{rSO}_{2}$ values. We recorded the $\mathrm{rSO}_{2}$ values at the time point of the initiation of surgical procedures because $\mathrm{rSO}_{2}$ values are considered relatively stable at that time.

\subsection{Outcome measurement}

The primary outcome in this study was the prediction of each outcome including death after pediatric cardiac surgery. We defined outcome as any of the following: (1) death within 30 days after surgery, or the need for (2) renal replacement therapy (RRT) or (3) ECMO, (4) mechanical ventilator-free days ( $<$ lower quartile: $<23$ days in all patients, $<22$ days in cyanotic patients and $<27$ days in non-cyanotic patients), or (5) shorten intensive care unit (ICU)-free survival day ( $<$ lower quartile: $<21$ days in all patients, $<19$ days in cyanotic patients and $<24$ days in non-cyanotic patients). The mechanical ventilator-free days and ICU-free days were calculated as 28 minus the number of days or part-days spent with mechanical ventilation or in the ICU during the first 28 days after surgery (excluding any days of ICU readmission); patients who died were assigned the worst possible outcome of zero mechanical ventilator-free days and ICU-free days. The criteria for extubation in the ICU include spontaneous ventilation, manageable airway secretion, $\mathrm{F}_{\mathrm{I}} \mathrm{O}_{2} \leq 0.4$, hemodynamic stability (dobutamine/dopamine $\leq 5 \mu \mathrm{g} / \mathrm{kg} / \mathrm{min}$ ), adequate cough reflex and spontaneous body movement. No patients after congenital heart disease were extubated in the operating room, even if the patients had Fontan circulation or Glenn circulation.

\subsection{Statistical analysis}

The statistical analysis was performed using EZR (Saitama Medical Center, Jichi Medical University, Saitama, Japan), which is a graphical user interface for R (The R Foundation for Statistical Computing, Vienna, Austria). Comparisons between the groups' demographic and surgical data were assessed using the unpaired Student's $t$ test or the Mann-Whitney $U$ test. A subgroup analysis was also performed in patients with cyanotic and non-cyanotic congenital heart disease. To determine an optimal cutoff value for $\mathrm{rSO}_{2}$ for the diagnosis of each outcome over time, we conducted a receiver operating characteristic (ROC) curve analysis. Optimal cutoff values were determined by using the Youden index. We estimated odds ratios (ORs) with their 95\% confidence intervals (95\% CIs) using Chi-square test to evaluate the risk of poor outcomes for $\mathrm{rSO}_{2}$ values below the optimal cutoff obtained from the ROC curve. Due to the small sample size that limited our ability to perform multivariable analyses, unadjusted odd ratios are presented. All data are presented as mean \pm SD or median (25th to 75 th percentile). A p-value $<0.05$ was considered significant.

\section{Results}

We included 59 patients: 31 patients had cyanotic heart disease, and 28 patients had non-cyanotic heart disease. Diagnosis of the patients was shown in Table 1 . Among all of the patients, 15 (25\%) patients were eligible for outcomes, including three deaths. None of the non-cyanotic heart patients died or needed RRT or ECMO. The $\mathrm{rSO}_{2}$ values were significantly lower in the patients with poor outcomes compared to those without poor outcomes (Table 2).

\subsection{Preoperative $\mathrm{rSO}_{2}$ and each outcome}

The ROC curves in all patients are shown Fig. 1. The ROC curves analysis revealed that both cerebral and renal $\mathrm{rSO}_{2}$ were good predictors of each outcomes in all patients (Table 3). The cerebral and renal $\mathrm{rSO}_{2}$ values were a good predictor for 30-day mortality after surgery in all patients. In addition, cerebral $\mathrm{rSO}_{2}$ showed better performance as a predictor of each type of outcome compared to renal $\mathrm{rSO}_{2}$ in all patients. The best cut-off cerebral and renal $\mathrm{rSO}_{2}$ values for each outcome in all patients were shown in Table 3 and the cut-off $\mathrm{rSO}_{2}$ values were associated with risk of mechanical ventilation-free day and ICU-free survival day [cerebral $\mathrm{rSO}_{2}$ : ORs of 6.87 (95\% CI 1.34-35.3, $\mathrm{p}=0.0211)$ and 6.87 (95\% CI 1.81-26.1, $\mathrm{p}=0.0046)$, and 
Table 1 Cardiac physiology groups

\begin{tabular}{ll}
\hline Group & Diagnosis \\
\hline 1: No cyanosis, no mixing & RVOT repair (2) \\
& Valve replacement/repair (1) \\
2: No cyanosis with $\mathrm{L} \rightarrow \mathrm{R}$ & VSD (15) \\
& ASD (5) \\
& cAVSD (4) \\
& Other (1) \\
& Fontan (1) \\
3: Cyanosis without $\mathrm{L} \rightarrow \mathrm{R}$ shunt & TOF (5) \\
4: Cyanosis with $\mathrm{L} \rightarrow \mathrm{R}$ shunt & TGA (4) \\
& Single ventricle, stage 1 (5) \\
& Single ventricle, stage 2 (2) \\
& TAPVR (2) \\
& CoA complex (3) \\
& DORV (3) \\
& PA/VSD (2) \\
& HLHS (1) \\
& Other (3) \\
\hline
\end{tabular}

$L \rightarrow R$ shunt left-to-right, $R V O T$ right ventricular outflow tract, VSD ventricular septal defect, $A S D$ arterial septal defect, $c A V S D$ complete atrioventricular septal defect, TOF tetralogy of Fallot, TGA transposition of the great arteries, CoA coarctation of aorta, DORV doubleoutlet right ventricle, $P A$ pulmonary atresia, $H L H S$ hypoplastic left heart syndrome

renal $\mathrm{rSO}_{2}$ : ORs of 7.50 (95\% CI 1.46-38.7, $\mathrm{p}=0.016$ ) and $12.0(95 \%$ CI $2.37-60.6, \mathrm{p}=0.0027)$, respectively] in all patients.

\subsection{Subgroup analysis}

The ROC curves of cerebral and renal $\mathrm{rSO}_{2}$ cut-off values that could be useful to identify patients with each type of outcome (Tables 4, 5) revealed that the cerebral $\mathrm{rSO}_{2}$ value was a good predictor for 30-day mortality after surgery in the cyanotic patients (Table 4). The best cut-off cerebral and renal $\mathrm{rSO}_{2}$ values for each outcome in cyanotic patients were shown in Table 4 and the cut-off $\mathrm{rSO}_{2}$ values of cerebral $\mathrm{rSO}_{2}$ were associated with risk of ventilatorfree day and ICU-free survival day [ORs of 22.8 (95\% CI 2.21-235.0, $\mathrm{p}=0.0087$ ) and 15.8 (95\% CI 1.53-164.0, $\mathrm{p}=0.0204)$, respectively] in the cyanotic patients.

However, in the non-cyanotic patients, the renal $\mathrm{rSO}_{2}$ value was a better predictor of each outcome than the cerebral $\mathrm{rSO}_{2}$ value (Table 5). The best cut-off cerebral and renal $\mathrm{rSO}_{2}$ values for each outcome in non-cyanotic patients were shown in Table 5. The cut-off cerebral $\mathrm{rSO}_{2}$ value was associated with risk of ventilator-free day [ORs of $11.3(95 \%$ CI 1.05-25.3, $\mathrm{p}=0.0456)$ ] and the cut-off renal $\mathrm{rSO}_{2}$ value was associated with risk of ICU-free survival day [ORs of 33.0 (95\% CI 2.25-484.0, $\mathrm{p}=0.0107)$ ] in the non-cyanotic patients.

\section{Discussion}

This retrospective study revealed that the cerebral $\mathrm{rSO}_{2}$ value obtained at the beginning of a pediatric patient's surgery could predict outcomes including death. This is in agreement with a large cohort study in which the preoperative $\mathrm{rSO}_{2}$ value was observed to be an independent predictor of short-and long-term mortality in adult cardiac patients [8]: the $\mathrm{rSO}_{2}$ value and 30-day mortality showed an AUC of $0.71(95 \%$ CI $0.68-0.73 ; \mathrm{p}<0.0001)$ and a cutoff value of $\leq 51 \%$. In addition, a recent retrospective study revealed that the baseline cerebral $\mathrm{rSO}_{2}$ value was associated with 30 -day mortality after left ventricular assist device surgery [13]. In addition, some studies have examined the utility of $\mathrm{rSO}_{2}$ values to predict poor outcomes in patients with congenital heart disease $[9,10]$. The pathophysiology and the surgery procedures for congenital heart disease are complex, and thus risk evaluations in congenital heart disease are difficult. However, the low baseline cerebral $\mathrm{rSO}_{2}$ value, especially less than $50 \%$, was associated with poor outcome in congenital heart disease pediatric patients and, interestingly, pediatric patients with left-to-right shunting rather than cyanotic had lower baseline cerebral $\mathrm{rSO}_{2}$ [9]. Our results were in-line of these previous studies and a preoperative $\mathrm{rSO}_{2}$ value might be useful for predicting the risk of outcome in congenital heart patients.

Our present findings suggest that $\mathrm{rSO}_{2}$ values are reflective of the severity of cardiopulmonary function. This may be due to the correlation $(\mathrm{r}=0.93, \mathrm{p}<0.0001)$ between the cerebral $\mathrm{rSO}_{2}$ and the $\mathrm{O}_{2}$ value obtained from the superior caval vein $\left(\mathrm{ScvO}_{2}\right)$ in pediatric cardiac patients [1]. It was also reported that changes in $\mathrm{rSO}_{2}$ reflected those in mixed venous oxygen saturation in adult cardiac patients [14]. BNP $[8,15]$ and left ventricular ejection fraction $[16,17]$ were described as factors that are significantly associated with baseline $\mathrm{rSO}_{2}$ values in cardiac patients. Additionally, multivariable regression analysis revealed that arterial saturation was significantly correlated with baseline cerebral $\mathrm{rSO}_{2}$ value $(\mathrm{r}=0.63, \mathrm{p}<0.001)$ [10]. Cardiopulmonary dysfunction before cardiac surgery increases the risk of low cardiac output syndrome, which is associated with morbidity and mortality. Considering the previous and present results, since low $\mathrm{rSO}_{2}$ values represent cardiopulmonary dysfunction in congenital heart patients, strict perioperative management must be used to prevent potentially life-threatening cardiopulmonary complications.

The present data suggest that renal $\mathrm{rSO}_{2}$ values were associated with outcomes in both cyanotic and noncyanotic patients, whereas cerebral $\mathrm{rSO}_{2}$ values were associated with outcomes only in the present cyanotic patients. This difference might be due to the impairment 
Table 2 Patient characteristics and perioperative data

\begin{tabular}{|c|c|c|c|c|c|c|c|c|c|}
\hline & \multicolumn{3}{|c|}{ All patients, $n=59$} & \multicolumn{3}{|c|}{ Cyanotic patients, $n=31$} & \multicolumn{3}{|c|}{ Non-cyanotic patients, $n=28$} \\
\hline & \multicolumn{2}{|l|}{ Poor outcomes } & \multirow[t]{2}{*}{$\mathrm{p}$} & \multicolumn{2}{|l|}{ Poor outcomes } & \multirow[t]{2}{*}{$\mathrm{p}$} & \multicolumn{2}{|l|}{ Poor outcomes } & \multirow[t]{2}{*}{$\mathrm{p}$} \\
\hline & $(-)$ & $(+)$ & & $(-)$ & $(+)$ & & $(-)$ & $(+)$ & \\
\hline Male/female (n) & $27 / 17$ & $9 / 6$ & 1.000 & $14 / 7$ & $6 / 4$ & 1.000 & $14 / 9$ & $2 / 3$ & 0.231 \\
\hline Age (months) & $15(5,33)$ & $3(0,9)$ & 0.005 & $7(1,15)$ & $6(0,9)$ & 0.594 & $27(11,55)$ & $7(4,21)$ & 0.016 \\
\hline Height (cm) & $77(19)$ & $57(12)$ & 0.001 & $64(11)$ & $58(13)$ & 0.205 & $86(20)$ & $69(18)$ & 0.096 \\
\hline $\begin{array}{l}\text { Body weight } \\
\text { (kg) }\end{array}$ & $9.7(5.5)$ & $4.9(3.0)$ & 0.002 & $6.2(3.0)$ & $5.5(3.5)$ & 0.531 & $12.2(6.0)$ & $7.1(4.4)$ & 0.087 \\
\hline $\begin{array}{l}\text { Body surface } \\
\text { area }\left(\mathrm{m}^{2}\right)\end{array}$ & $0.47(0.18)$ & $0.31(0.12)$ & 0.002 & $0.36(0.11)$ & $0.30(0.13)$ & 0.240 & $0.54(0.18)$ & $0.37(0.15)$ & 0.067 \\
\hline $\mathrm{F}_{\mathrm{I}} \mathrm{O}_{2}$ & $0.4(0.3,0.4)$ & $0.4(0.21,0.6)$ & 0.893 & $0.4(0.4,0.6)$ & $0.4(0.21,0.6)$ & 0.307 & $0.4(0.3,0.4)$ & $0.4(0.3,0.4)$ & 0.770 \\
\hline $\mathrm{SpO}_{2}(\%)$ & $99(90,100)$ & $86(79,94)$ & 0.003 & $86(77,92)$ & $85(79,91)$ & 0.966 & $99(1)$ & $98(2)$ & 0.065 \\
\hline HR (bpm) & $113(21)$ & $121(14)$ & 0.161 & $126(18)$ & $121(16)$ & 0.435 & 105 (18) & $104(18)$ & 0.893 \\
\hline MAP (mmHg) & $61(16)$ & $52(13)$ & 0.062 & $52(12)$ & $51(12)$ & 0.890 & $68(15)$ & $53(10)$ & 0.048 \\
\hline $\begin{array}{l}\text { Cerebral } \mathrm{rSO}_{2} \\
(\%)\end{array}$ & $65(12)$ & $54(9)$ & 0.001 & $59(11)$ & $50(5)$ & 0.021 & $70(9)$ & $62(13)$ & 0.105 \\
\hline Renal $\mathrm{rSO}_{2}(\%)$ & $69(13)$ & $53(12)$ & $<0.001$ & $59(15)$ & $51(14)$ & 0.015 & 77 (10) & $61(14)$ & 0.011 \\
\hline $\begin{array}{l}\text { Renal-cerebral } \\
\mathrm{rSO}_{2}(\%)\end{array}$ & $3.9(12.1)$ & $-1.0(11.0)$ & 0.176 & $-0.2(12.6)$ & 0.9 (11.6) & 0.812 & $7(11)$ & $0(12)$ & 0.250 \\
\hline $\begin{array}{l}\text { Preoperative } \\
\text { BNP (pg/mL) }\end{array}$ & $31(17,66)$ & $140(94,750)$ & 0.001 & $68(21,506)$ & $114(94,541)$ & 0.163 & $30(18,52)$ & $63(51,492)$ & 0.141 \\
\hline $\begin{array}{l}\text { Preoperative } \\
\text { Cre }(\mathrm{mg} / \mathrm{dL})\end{array}$ & $0.30(0.23,0.34)$ & $0.38(0.24,0.52)$ & 0.102 & $0.31(0.23,0.36)$ & $0.40(0.26,0.66)$ & 0.095 & $0.32(0.21)$ & $0.29(0.09)$ & 0.652 \\
\hline $\begin{array}{l}\text { Preoperative } \mathrm{Hb} \\
(\mathrm{g} / \mathrm{dL})\end{array}$ & $11.5(2.0)$ & $12.0(1.4)$ & 0.364 & $12.3(2.4)$ & $12.4(0.9)$ & 0.931 & $11.0(1.1)$ & $10.2(4.7)$ & 0.286 \\
\hline $\begin{array}{l}\text { Preoperative } \\
\text { mechanical } \\
\text { ventilation (n) }\end{array}$ & 4 & 9 & 0.001 & 6 & 6 & 0.127 & 0 & 1 & 0.179 \\
\hline $\begin{array}{l}\text { Preoperative } \\
\text { inotropic sup- } \\
\text { port (n) }\end{array}$ & 1 & 4 & 0.013 & 0 & 3 & 0.027 & 0 & 2 & 0.026 \\
\hline \multicolumn{10}{|l|}{ RACHS-1 (n) } \\
\hline 1 & 6 & 0 & 0.088 & 0 & 0 & 0.420 & 5 & 1 & 0.763 \\
\hline 2 & 23 & 5 & & 7 & 2 & & 16 & 3 & \\
\hline 3 & 11 & 7 & & 9 & 6 & & 2 & 1 & \\
\hline 4 & 4 & 2 & & 5 & 1 & & 0 & 0 & \\
\hline 6 & 0 & 1 & & 0 & 1 & & 0 & 0 & \\
\hline $\begin{array}{l}\text { Duration of } \\
\text { surgery (min) }\end{array}$ & $237(74)$ & 334 (194) & 0.007 & $279(71)$ & $377(244)$ & 0.098 & $210(63)$ & $238(66)$ & 0.378 \\
\hline $\begin{array}{l}\text { Duration of } \\
\text { CPB }\end{array}$ & $99(69,127)$ & $144(95,239)$ & 0.017 & $116(88,173)$ & $165(92,307)$ & 0.170 & $94(61,114)$ & $92(9,157)$ & 0.384 \\
\hline $\begin{array}{l}\text { Duration of } \\
\text { aortic clamp }\end{array}$ & $49(15,63)$ & $18(0,69)$ & 0.208 & $35(80,100)$ & $9(0,34)$ & 0.520 & $55(32,62)$ & $47(20,52)$ & 0.401 \\
\hline $\begin{array}{l}\text { Duration of } \\
\text { anesthesia } \\
\text { (min) }\end{array}$ & $330(87)$ & 458 (217) & 0.003 & $385(88)$ & 482 (259) & 0.130 & $296(71)$ & 341 (104) & 0.245 \\
\hline
\end{tabular}

Mean (SD) median (interquartile range), $H R$ heart rate, $M A P$ mean arterial pressure, $r \mathrm{SO}_{2}$ regional oxyhemoglobin saturation, $B N P$ brain natriuretic peptide, $C r e$ serum creatinine, $R A C H S-1$ Risk Adjusted Classification for Congenital Heart Surgery-1

of cerebrovascular autoregulation in the cyanotic patients. In normal infants, the renal $\mathrm{rSO}_{2}$ value is higher compared to the cerebral $\mathrm{rSO}_{2}$ value, and the cerebral $\mathrm{rSO}_{2}$ value remains unchanged due to the cerebrovascular autoregulation even though the renal $\mathrm{rSO}_{2}$ value decreases when the hemodynamic status is unstable [18]. Impaired cerebrovascular autoregulation was found in approx. $40 \%$ of preterm infants [19]. Impaired cerebrovascular 
Fig. 1 Receiver-operating characteristic curves comparing the ability of regional oxygen saturation to predict each outcome in all patients. a Renal replacement therapy; b extracorporeal membrane oxygenation; $\mathbf{c}$ intensive care unit-free survival day; $\mathbf{d}$ mechanical ventilator-free day, $r \mathrm{SO}_{2}$ reginal oxyhemoglobin saturation
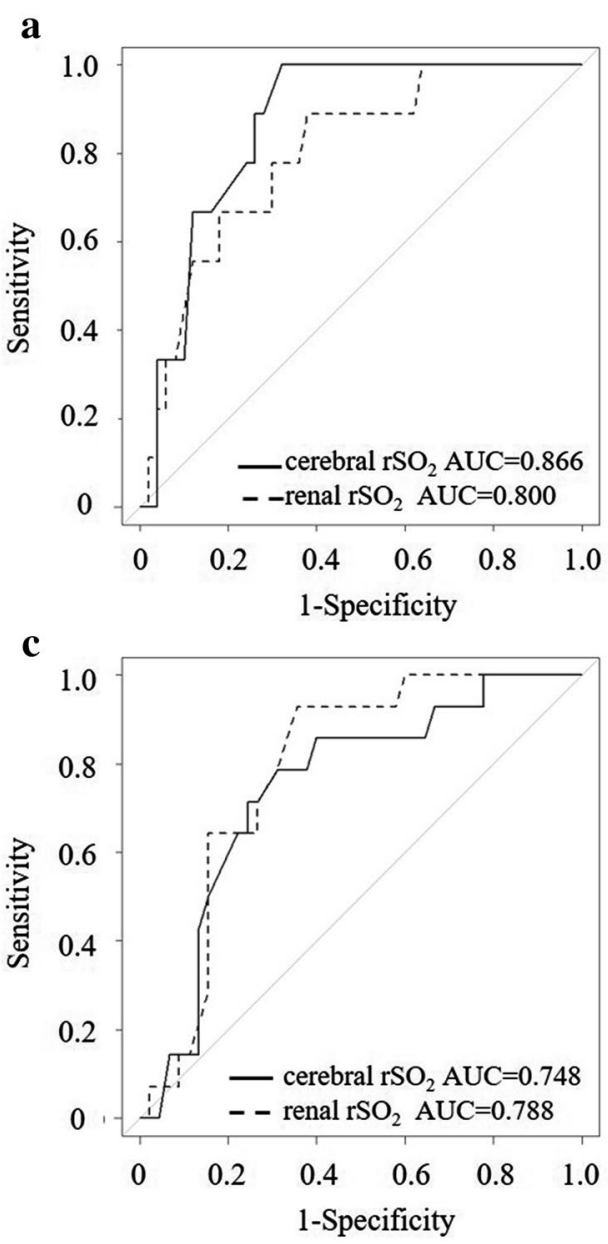

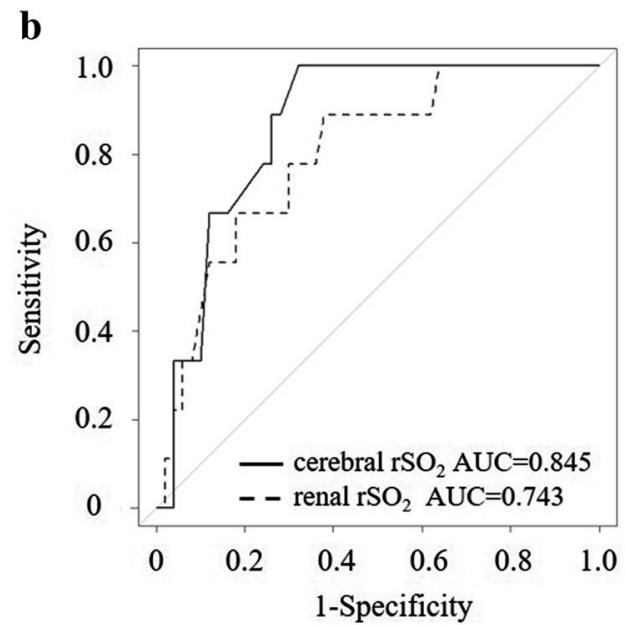

d

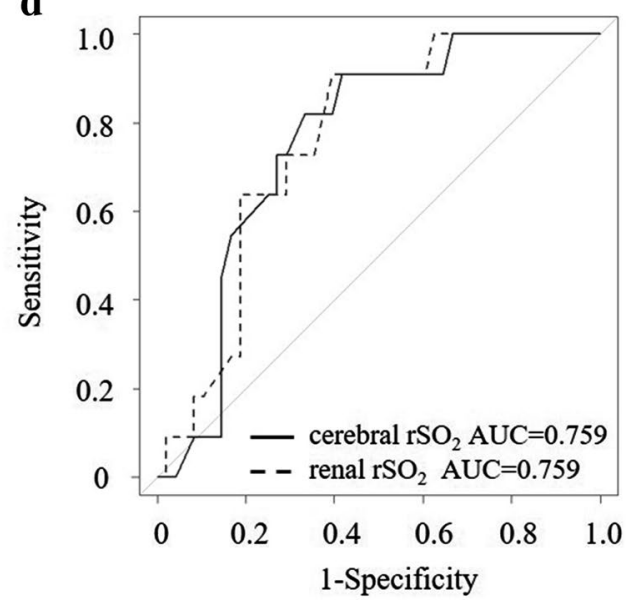

Table 3 Optimal cut-off values of $\mathrm{rSO}_{2}$ for the prediction of poor outcomes in all patients $(\mathrm{n}=59)$

\begin{tabular}{lclllll}
\hline & $\mathrm{n}$ & $\mathrm{rSO}_{2}$ & Cut-off $(\%)$ & AUC (95\% CI) & Sensitivity & Specificity \\
\hline RRT & 9 & Cerebral & 58 & $0.866(0.770-0.961)$ & 1.000 & 0.680 \\
& & Renal & 66 & $0.800(0.652-0.948)$ & 0.889 & 0.620 \\
ECMO & \multirow{2}{*}{7} & Cerebral & 58 & $0.845(0.733-0.956)$ & 1.000 & 0.654 \\
& & Renal & 66 & $0.743(0.565-0.921)$ & 0.857 & 0.596 \\
Mechanical ventilator-free day (<23 days) & \multirow{2}{*}{11} & Cerebral & 61 & $0.759(0.623-0.894)$ & 0.909 & 0.583 \\
& & Renal & 67 & $0.759(0.627-0.892)$ & 0.909 & 0.604 \\
ICU-free survival day (<21 days) & \multirow{2}{*}{14} & Cerebral & 58 & $0.748(0.606-0.891)$ & 0.786 & 0.689 \\
& & Renal & 67 & $0.788(0.670-0.906)$ & 0.929 & 0.644 \\
Death within 30 days & \multirow{2}{*}{3} & Cerebral & 51 & $0.887(0.794-0.980)$ & 1.000 & 0.839 \\
& & Renal & 66 & $0.777(0.537-1.000)$ & 1.000 & 0.571 \\
\hline
\end{tabular}

$E C M O$ extracorporeal membrane oxygenation, $R R T$ renal replacement therapy

autoregulation was also detected in patients with congenital heart disease and was associated with abnormal prenatal neurologic development [20]. In addition, the absence of cerebrovascular autoregulation was associated with adverse outcomes in preterm infants [21]. These findings suggest that impaired cerebrovascular autoregulation caused parallel changes in both cerebral and renal $\mathrm{rSO}_{2}$ in cyanotic patients. Therefore, prompt intervention: red blood cell transfusion; administration of inotropic drugs; and changing mechanical ventilation setting; to lower the cerebral $\mathrm{rSO}_{2}$ value may be required to improve the clinical outcomes of cyanotic patients. 
Table 4 Optimal cut-off values of $\mathrm{rSO}_{2}$ for the prediction of poor outcomes in the cyanotic patients $(\mathrm{n}=31)$

\begin{tabular}{lllllll}
\hline & $\mathrm{n}$ & $\mathrm{rSO}_{2}$ & Cut-off $(\%)$ & AUC (95\% CI) & Sensitivity & Specificity \\
\hline RRT & 9 & Cerebral & 58 & $0.747(0.572-0.923)$ & 1.000 & 0.500 \\
& & Renal & 53 & $0.672(0.451-0.892)$ & 0.667 & 0.682 \\
ECMO & \multirow{2}{*}{7} & Cerebral & 51 & $0.717(0.524-0.911)$ & 0.714 & 0.750 \\
& & Renal & 53 & $0.586(0.331-0.841)$ & 0.571 & 0.625 \\
Mechanical ventilator-free day (<22 days) & \multirow{2}{*}{6} & Cerebral & 51 & $0.757(0.590-0.923)$ & 0.833 & 0.760 \\
& & Renal & 53 & $0.570(0.299-0.841)$ & 0.667 & 0.640 \\
ICU -free survival day (<19 days) & \multirow{2}{*}{7} & Cerebral & 51 & $0.801(0.646-0.955)$ & 0.857 & 0.792 \\
& & Renal & 53 & $0.607(0.362-0.852)$ & 0.714 & 0.667 \\
Death within 30 days & \multirow{2}{*}{3} & Cerebral & 51 & $0.798(0.637-0.958)$ & 1.000 & 0.714 \\
& & Renal & 66 & $0.631(0.249-1.000)$ & 1.000 & 0.321 \\
\hline
\end{tabular}

ECMO extracorporeal membrane oxygenation, $R R T$ renal replacement therapy

Table 5 Optimal cut-off values of $\mathrm{rSO}_{2}$ for the prediction of poor outcomes in the noncyanotic patients $(n=28)$

\begin{tabular}{lllllll}
\hline & $\mathrm{n}$ & $\mathrm{rSO}_{2}$ & Cut-off $(\%)$ & $\mathrm{AUC}(95 \% \mathrm{CI})$ & Sensitivity & Specificity \\
\hline $\begin{array}{l}\text { Mechanical } \\
\text { ventilator-free }\end{array}$ & 5 & Cerebral & 66 & $0.809(0.616-1.000)$ & 0.800 & 0.739 \\
$\begin{array}{c}\text { day }(<27 \text { days }) \\
\text { ICU-free sur- }\end{array}$ & 4 & Cenal & 71 & $0.845(0.682-1.000)$ & 1.000 & 0.696 \\
$\begin{array}{l}\text { vival day }(<24 \\
\text { days })\end{array}$ & & Renal & 66 & $0.536(0.149-0.923)$ & 0.750 & 0.583 \\
\hline
\end{tabular}

In the present analyses, not only the $\mathrm{rSO}_{2}$ values but also the patients' age, physique (height, body weight, and body surface area), $\mathrm{SpO}_{2}$, and the duration of surgery and anesthesia differed significantly between the patients with poor outcomes and those without poor outcomes in all patients and in the non-cyanotic patients. In contrast, only the $\mathrm{rSO}_{2}$ value was different in the cyanotic patients. The following may explain the differences in our findings between all patients, non-cyanotic patients, and cyanotic patients. The severity of the heart disease was different between the cyanotic and non-cyanotic patients. In general, cyanotic congenital heart disease is more severe compared to non-cyanotic congenital heart disease, and it requires surgical repair during the neonatal period. The surgical repair of cyanotic heart disease is more complicated and takes longer compared to the surgery for non-cyanotic congenital heart disease. Thus, patient age, physique, $\mathrm{SpO}_{2}$ and the duration of surgery and anesthesia were significantly different between our patients with or without poor outcomes in the total patient series.

Limitations of this study should be considered. First, as the study was retrospective with a small sample size, we could not perform multivariable analyses, and confounding factors might thus have affected the results. Additionally, due to a small sample size, the $95 \%$ confidence intervals of the AUC of ROC curve for prediction of some of poor outcomes were relatively wide. Further studies with larger numbers of patients are needed to test our findings. Second, we classified the patients into cyanotic and non-cyanotic patients, however the classification is difficult. Tetralogy of Fallot is usually classified into cyanotic congenital heart disease but in some cases, patients with mild right ventricular outflow tract (RVOT) obstruction do not show cyanosis. In our study, all patients with tetralogy of Fallot have moderate to severe RVOT obstruction so we classified these patients into the cyanotic congenital heart disease. Third, $\mathrm{rSO}_{2}$ was measured at one point in time in this study. The trend of $\mathrm{rSO}_{2}$ values might be a better predictor of poor outcomes. The utility of a $\mathrm{rSO}_{2}$ desaturation score was reported by Slater and colleagues, and which was associated with an increased risk of cognitive decline and prolonged hospital stay [22]. The intraoperative $\mathrm{rSO}_{2}$ desaturation score was also a predictor of postoperative low cardiac output state [23]. We should pay attention not only absolute value but also trend of $\mathrm{rSO}_{2}$ values to prevent or reduce the severity of life-threatening complication. Fourth, the $\mathrm{rSO}_{2}$ values at the beginning of each surgery were measured under general anesthesia and mechanical ventilation with different fraction of inspired oxygen $\left(\mathrm{F}_{\mathrm{I}} \mathrm{O}_{2}\right)$ levels and hemoglobin concentration. These might have impact on $\mathrm{rSO}_{2}$ values, but $\mathrm{F}_{\mathrm{I}} \mathrm{O}_{2}$ and hemoglobin concentration were no significantly different between patients with and without poor outcomes. Additionally, the measurement of a pediatric patient's $\mathrm{rSO}_{2}$ value in the fully awake condition is difficult, and we want to avoid the misregistration of erroneous values by artifact and crying which increases the oxygen consumption leading to lower $\mathrm{rSO}_{2}$. Thus, we decided to measure the $\mathrm{rSO}_{2}$ under 
a stable condition with general anesthesia and mechanical ventilation, which may reflect cardiopulmonary function.

The mortality and morbidity after congenital heart surgery are usually dependent on not only the patient's preoperative cardiopulmonary function but also the surgical procedure, the anesthetic management, the postoperative care and other factors. Nevertheless, our analyses revealed that the $\mathrm{rSO}_{2}$ value (which reflects preoperative cardiopulmonary function) can be a predictor of outcomes, and this indicates that preoperative cardiopulmonary function is a major factor associated with outcomes after congenital cardiac disease surgery.

In conclusion, despite of the small sample size in this study, the preoperative low $\mathrm{rSO}_{2}$ value was associated with outcomes including 30-day mortality and might be reflective of the severity of cardiopulmonary function. Further studies are needed to confirm our positive results.

Author contributions J.S. designed the study, collected the data, performed the statistical analysis and drafted the manuscript. D.K., J.K., T.S., M.S. collected the data and analysis the data. S.N., T.T. and E.H. collected and evaluated the data, revised the manuscript. K.H. designed the study, evaluated the data and extensively revised the manuscript.

Funding This work was supported by the Department of Anesthesiology, Hirosaki University Graduate School of Medicine.

\section{Compliance with ethical standards}

Conflict of interest All authors declare no conflict of interest. All authors read and approved the final manuscript and attest to the integrity of the original data and the analysis reported in this manuscript.

\section{References}

1. Nagdyman N, Ewert P, Peters B, et al. Comparison of different near-infrared spectroscopic cerebral oxygenation indices with central venous and jugular venous oxygenation saturation in children. Paediatr Anaesth. 2008;18:160-6.

2. Murkin JM, Adams SJ, Novick RJ, et al. Monitoring brain oxygen saturation during coronary bypass surgery: a randomized, prospective study. Anesth Analg. 2007;104:51-8.

3. Yao FS, Tseng CC, Ho CY, et al. Cerebral oxygen desaturation is associated with early postoperative neuropsychological dysfunction in patients undergoing cardiac surgery. J Cardiothorac Vasc Anesth. 2004;18:552-8.

4. Choi DK, Kim WJ, Chin JH, et al. Intraoperative renal regional oxygen desaturation can be a predictor for acute kidney injury after cardiac surgery. J Cardiothorac Vasc Anesth. 2013;28:564-71.

5. Hazle MA, Gajarski RJ, Aiyagari R, et al. Urinary biomarkers and renal near-infrared spectroscopy predict intensive care unit outcomes after cardiac surgery in infants younger than 6 months of age. J Thorac Cardiovasc Surg. 2013;146:861-7.

6. Ruf B, Bonelli V, Balling G, et al. Intraoperative renal nearinfrared spectroscopy indicates developing acute kidney injury in infants undergoing cardiac surgery with cardiopulmonary bypass: a case-control study. Crit Care. 2015;19:27.
7. Owens GE, King K, Gurney JG, et al. Low renal oximetry correlates with acute kidney injury after infant cardiac surgery. Pediatr Cardiol. 2011;32:183-8.

8. Heringlake M, Garbers C, Käbler JH, et al. Preoperative cerebral oxygen saturation and clinical outcomes in cardiac surgery. Anesthesiology. 2011;114:58-69.

9. Fenton KN, Freeman K, Glogowski K, et al. The significance of baseline cerebral oxygen saturation in children undergoing congenital heart surgery. Am J Surg. 2005;90:260-3.

10. Kurth CD, Steven JL, Montenegro LM, et al. Cerebral oxygen saturation before congenital heart surgery. Ann Thorac Surg. 2001;72:187-92.

11. Licht DJ, Wang J, Silvestre DW, et al. Preoperative cerebral blood flow is diminished in neonates with severe congenital heart defects. J Thorac Cardiovasc Surg. 2004;128:841-9.

12. Kredel M, Lubnow M, Westermaier T, et al. Cerebral tissue oxygenation during the initiation of venovenous ECMO. ASAIO J. 2014;60:694-700.

13. Ghosal S, Trivedi J, Chen J, et al. Regional cerebral oxygen saturation level predicts 30-day mortality rate after left ventricular assist device surgery. J Cardiothorac Vasc Anesth. 2018;32:1185-90.

14. Dullenkopf A, Baulig W, Weiss M, et al. Cerebral near-infrared spectroscopy in adult patients after cardiac surgery is not useful for monitoring absolute values but may reflect trends in venous oxygenation under clinical conditions. J Cardiothrac Vasc Anesth. 2007;21:535-9.

15. Yamamoto M, Hayashida M, Kakemizu-Watanabe $M$, et al. B-Type Natriuretic peptide and hemoglobin are two major factors significantly associated with baseline cerebral oxygen saturation measured using the INVOS oximeter in patients undergoing offpump coronary artery bypass graft surgery. J Cardiothorac Vasc Anesth. 2018;32:187-96.

16. Kobayashi K, Kitamura T, Kohira S, et al. Factors associated with a low initial cerebral oxygen saturation value in patients undergoing cardiac surgery. J Artif Organs. 2017;20:110-6.

17. Paquet C, Deschamps A, Denault AY, et al. Baseline regional cerebral oxygen saturation correlates with left ventricular systolic and diastolic function. J Cardiothorac Vasc Anesth. 2008;22:840-6.

18. Hoffman GM, Ghanayem NS, Tweddell JS. Noninvasive assessment of cardiac output. Semin Thorac Cardiovasc Surg Pediatr Card Surg Ann. 2005;8:12-21.

19. Verhagen EA, Hummel LA, Bos AF, et al. Near-infrared spectroscopy to detect absence of cerebrovascular autoregulation in preterm infants. Clin Neurophysiol. 2014;125:47-52.

20. Arduini M, Rosati P, Caforio L, et al. Cerebral blood flow autoregulation and congenital heart disease: possible causes of abnormal prenatal neurologic development. J Matern Fetal Neonatal Med. 2011;24:1208-11.

21. Wong FY, Leung TS, Austin T, et al. Impaired autoregulation in preterm infants identified by using spatially resolved spectroscopy. Pediatrics. 2008;121:e604-11.

22. Slater JP, Guarino T, Stack J, et al. Cerebral oxygen desaturation predicts cognitive decline and longer hospital stay after cardiac surgery. Ann Thorac Surg. 2009;87:36-45.

23. Zulueta JL, Vida VL, Perisinotto E, et al. Role of intraoperative regional oxygen saturation using near infrared spectroscopy in the prediction of low output syndrome after pediatric heart surgery. $\mathrm{J}$ Card Surg. 2013;28:446-52.

Publisher's Note Springer Nature remains neutral with regard to jurisdictional claims in published maps and institutional affiliations. 


\title{
Affiliations
}

\section{Junichi Saito ${ }^{1}$ (1) - Daiki Takekawa ${ }^{1}$. Jun Kawaguchi ${ }^{1} \cdot$ Takuya Suganuma $^{1} \cdot$ Mao Konno $^{1}$ - Satoko Noguchi ${ }^{1}$. Takaharu Tokita $^{2} \cdot$ Eiji Hashiba $^{3} \cdot$ Kazuyoshi Hirota $^{1}$}

\author{
Daiki Takekawa \\ takekawa.daiki50@gmail.com \\ Jun Kawaguchi \\ jkawaguchi3@gmail.com \\ Takuya Suganuma \\ tkuyoung@gmail.com \\ Mao Konno \\ mao_t5r1@yahoo.co.jp \\ Satoko Noguchi \\ satko1110@yahoo.co.jp \\ Takaharu Tokita \\ tokita0417@gmail.com
}

Eiji Hashiba

ehashiba@hirosaki-u.ac.jp

Kazuyoshi Hirota

hirotak@hirosaki-u.ac.jp

1 Department of Anesthesiology, Hirosaki University Graduate School of Medicine, 5 Zaifu-cho, Hirosaki 036-8562, Japan

2 Department of Anesthesiology, Aomori Prefectural Central Hospital, Aomori, Japan

3 Division of Intensive Care Unit, Hirosaki University Graduate School of Medicine, Hirosaki, Japan 